\title{
A POLÍTICA E A SOCIEDADE CIVIL COMO PRESSUPOSTOS DA LIBERDADE SOCIAL DO INDIVÍDUO: a contribuição de John Locke para a fundamentação da modernidade
}

The politics and the civil society as presumptions of individual social freedom: the contributions of John Locke as fundamentalism modernity

\section{Ascísio dos Reis Pereira}

Doutor em Educação pela UNICAMP. Professor do curso de Filosofia da PUCPR, Curitiba, PR - Brasil, e-mail: ascisio@ bol.com.br

\begin{abstract}
Resumo
Neste texto, buscaremos apresentar as afirmações trabalhadas pelo pensador inglês John Locke que, ao forjar uma idéia de sociedade no século dezessete, mostra uma forma para que a sociedade assimile o que foi por ele proposto, que é a formação do homem mediante um projeto político, com os pressupostos do liberalismo por ele defendido. O ponto de partida que será destacado é que ao formarem a sociedade civil, os homens a compreenderam como uma forma de organização política, criando-se, assim, uma forma institucional para que pudessem ficar vinculados a alguma coisa que lhes trouxesse garantias e é sempre bom lembrar que a busca de tais garantias refere-se à proteção da vida, da segurança pessoal e, principalmente, das suas propriedades. Que é, ainda dentro do estado de natureza, que os homens fizeram a experiência do conhecimento da liberdade e, portanto, não tem sentido algum perder por completo algo que foi difícil de conquistar.
\end{abstract}

Palavras-chave: Sociedade civil; Natureza; Liberdade e política. 


\section{Abstract}

This text seeks to introduce the statements worked by the english thinker John Locke who, when forging an idea of society in the seventeen century, shows for the society a way to assimilate what has been proposed by him, which is the formation of the man through a political project, with the assumptions of liberalism argued by him. The initial point that will be highlighted is that, when forming the civil society, the men understood it as a form of political organization, so creating an institutional way so they could be bound to anything that could bring them guarantees, and it is always good to remember that the pursuit of such guarantees comes to the protection of life, personal security and mainly, of their property. That is, still in the state of nature, that men had the experience of knowledge of freedom, and so does not make any sense to lose at all something that was difficult to conquer.

Keywords: Civil society; Nature; Freedom and politics.

\section{Introdução}

Quando fazemos referências à sociedade civil no pensamento de Locke, é importante ressaltar que ela é vista por ele como um processo de superação do próprio estado de natureza. Entretanto, o inconveniente causado ao homem pelo estado de natureza consiste, fundamentalmente, na administração de alguns conflitos, como o de se tomar decisões racionais acerca da proteção da vida, das propriedades e de como fazer julgamentos em questões conflituosas. Porém, por se tratar de um momento em que é total a liberdade, pois no estado de natureza é o bem fundamental e único realmente possuído pelos indivíduos. Como em geral, para Locke, o estado de natureza é bom e favorável ao homem, por que então ele deveria ser superado? Porque por meio da sociedade civil se ampliaria a garantia da liberdade com a formulação das leis e dos direitos adquiridos no chamado estado de natureza. Assim, este processo permite aos componentes da sociedade uma maior segurança no que se refere à garantia, à manutenção e à ampliação da própria liberdade, com a segurança legal permitida pelas leis. E, neste ponto, há uma questão que suscita reflexão: de que forma Locke comprova tal afirmação? 
O ponto de partida que será destacado é que, ao formarem a sociedade civil, os homens a compreenderam como uma forma de organização política, criando-se, assim, uma forma institucional para que pudessem ficar vinculados a alguma coisa que lhes trouxesse garantias e é sempre bom lembrar que a busca de tais garantias refere-se à proteção da vida, da segurança pessoal e, principalmente, das suas propriedades. Que é, ainda dentro do estado de natureza e de plena liberdade, que os integrantes da comunidade tornaram-se proprietários dos bens materiais e fizeram a experiência do conhecimento da liberdade e, portanto, não tem sentido algum perder algo que foi difícil de conquistar.

Entre as muitas questões que se apresentaram para as comunidades no estado de natureza, uma de grande significado é certamente a garantia da paz e, por isso, não pode ser admitido jamais o estado de guerra, pois este acabaria com a segurança dos indivíduos, tanto no que se refere à preservação da própria vida ou ainda na forma de preservação das propriedades.

Partindo-se de necessidades como estas que aqui relatamos, fezse necessária a criação e organização da sociedade civil e esta questão apresentouse como crucial aos integrantes da comunidade. Tal posição fica claramente definida dentro do pensamento lockiano. Esta reflexão é demonstrada em muitas passagens do seu segundo tratado, não sendo, no entanto, um raciocínio que se apresente exclusivamente nesta obra, mas já aparecera também no primeiro tratado. Sendo constituída desta forma a sociedade civil, passo importante dentro do pensamento político de Locke. É também vista por ele como um momento de evolução da sociedade ou da relação de amadurecimento dos indivíduos que estão vivendo em comunidade.

\section{A necessidade da sociedade civil}

Desenvolver e ampliar os pontos importantes para a organização política da sociedade constitui-se para Locke em uma conquista do homem livre e racional que, por extensão, é, em certa medida, uma herança do estado de natureza, pois este era de plena liberdade. Dessa forma, após rejeitar uma concepção absolutista de política ou de governo, essa rejeição está fundamentalmente em suas críticas e embates com o pensamento de Robert Filmer, teses presentes em seu Primeiro tratado sobre o Governo. Os homens, segundo Locke, buscam criar uma sociedade com autonomia e poder de regulamentação, além do controle social sobre o poder que foi constituído. 
É esse avanço ou evolução da organização humana que Locke procura demonstrar quando discute a sociedade civil. Essa forma de organização dos indivíduos, que é legítima, traz também uma questão crucial para o seu pensamento, que é o direito de estabelecer algum controle sobre o governo. E, neste ponto, está aparente mais uma vez o enfrentamento direto com o modo absolutista de controlar o Estado, alvo de duras e severas críticas por ele desenvolvidas anteriormente.

Por romper com a monarquia controladora e herdeira da tradição política medieval, que tem o princípio de manter unida a questão da política e da religião, Locke constrói uma forma de pensar a sua política tendo como pontos fundamentais princípios como: romper com a tradição absolutista, pensamento que para ele era ultrapassado; construção de uma nova concepção para a organização da política, embora admita a manutenção da monarquia. Propõe formas de controle sobre o exercício do poder e neste ponto torna-se possível no pensamento político lockiano o surgimento de mecanismos como a sociedade civil, pelo que podemos certamente afirmar que Locke é um pensador que considera necessário separar Igreja e Estado como marcas de suas teses enquanto um pensador eminentemente moderno.

Antes de definir em que consiste a sociedade política ou civil, Locke faz referências à primeira forma de sociedade constituída pelos homens que, segundo ele, seria aquela formada entre o homem e a mulher, o que deu início à relação existente entre pais e filhos, juntando-se posteriormente com a sociedade, que passou a existir entre senhor e servidor. Embora fossem essas sociedades muito importantes e significativas, não formavam uma comunidade política, pois havia inúmeros limites dentro destas relações sociais. O ponto de partida inaugurado por Locke é por um lado biológico e por outro teológico, pois estabelece, em primeiro lugar, que a união mantida entre homem e mulher tem por princípios a procriação, além de buscarem, conjuntamente, a manutenção dos filhos, até o justo momento em que estes possam se cuidar e alimentaremse por si mesmos; é também uma comparação estabelecida a partir da relação existente entre as diversas espécies de animais presentes na natureza, o que parece, por um lado, um Locke naturalista que, no entanto, não abandona os propósitos teológicos e religiosos inteiramente presentes em sua obra.

Ao explicar com bastante ênfase o sentido da união conjugal entre homem e mulher, Locke faz uma reflexão muito significativa para a fundamentação da sua proposta política, pois os argumentos que são apresentados por ele demonstram uma distinção humana daquilo que são as percepções dos animais, o que é possível por ser feita nos humanos por meio do uso da razão. Isso por um 
lado, por outro lado, é uma atitude racional sustentada a partir da revelação divina, é, entretanto, o primado da criação, visto que é admitido por ele que Deus permitiu ao homem fazer distinções diferentes daquelas feitas pelos animais tidos como não-racionais e este fato teria permitido aos homens a possibilidade de constituírem a primeira sociedade que é a família. É da família que surge uma questão bem presente no pensamento lockiano, que é a de garantir a propriedade mediante o controle que o homem tem sobre seus filhos, e sendo assim, estabelece-se um claro princípio para a garantia da propriedade. A construção engenhosa do pensamento de Locke pode ser percebida nesta passagem:

E nisso reside, penso eu, a principal razão, se não a única, pela qual, na raça humana, macho e fêmea permanecem unidos mais tempo do que entre as outras criaturas, a saber, porque a mulher é capaz de conceber e, de fato, muitas vezes fica de novo grávida e dá à luz muito antes que o rebento anterior tenha saído da dependência da ajuda dos pais para o seu sustento e seja capaz de mover-se por si mesmo, recebendo a assistência que lhe é devida de seus pais: pelo que o pai, que está obrigado a cuidar daqueles que gerou, está sob a obrigação de continuar em sociedade conjugal com a mesma mulher por mais tempo que as outras criaturas, cujos filhotes são capazes de subsistir por seus próprios meios antes que o momento da procriação chegue novamente; o laço conjugal dissolve-se por si mesmo, deixando-as em liberdade até que o bimeneu, em sua época costumeira, as convoque mais uma vez a escolher novos companheiros. (LOCKE, 1998, p. 453).

Locke elabora também a sua moral das relações conjugais, dando ênfase para a questão da relação duradoura entre os casais, ficando bem clara a noção de responsabilidade colocada para a constituição da família enquanto uma sociedade, decorrendo-se daí que os papéis a serem desenvolvidos tanto pelo pai, assim como pela mãe, estão bem definidos. Ao estabelecer uma sociedade, é necessário que haja regras; e embora a família não se caracterize como uma sociedade política, deve haver dentro dela normas reguladoras das relações, proporcionando assim, em primeiro lugar, uma convivência pacífica entre seus integrantes, pois cada um já sabe o papel que lhe cabe, mas Locke demonstra claramente também que a partir da própria organização familiar podese estabelecer os princípios dos bens materiais, como ele mesmo afirma:

No que não se pode deixar de admirar aí a sabedoria do grande criador que, tendo dado ao homem a capacidade de previsão e de planejar para o futuro, bem como de suprir as necessidades presentes, tornou necessário 
que a sociedade entre homem e mulher fosse mais duradoura do que entre os machos e as fêmeas de outras criaturas, de modo que seu esforço seja estimulado e seus interesses mais bem unidos, para fazer provisões e acumular bens para sua progênie comum, que uma mistura incerta ou interrupções fáceis e frequientes da sociedade conjugal poderiam grandemente perturbar. (LOCKE, 1998, p. 453-454).

Diante desta postura colocada por Locke, podemos perceber com muita clareza a sua defesa da importância da família como organização. A visão demonstrada por ele é muito direta e objetiva quanto ao destaque dado para a formação da família, sendo esta uma das formas mais importantes para a constituição de uma sociedade com princípios e normas e que, assim, poderia contribuir com seu exemplo na organização política da comunidade.

Outra questão importante para a compreensão da organização social é a busca por garantias e pelo controle, em primeiro lugar, do próprio princípio da família em que a união conjugal monogâmica permitiria a segurança e a certeza sobre quem é o pai e quem são os filhos e definindo-se, desta forma, o direito de herança, demonstrando mais uma vez a importância do princípio da propriedade particular, buscando garantir a manutenção dos bens por meio da organização familiar entre os pais e os filhos.

A organização da família é um elemento fundamental para a sociedade civil. É também um momento decisivo dentro das argumentações apresentadas por Locke, pois cria, a partir da ordem familiar, um pacto, que é estabelecido entre o marido e a esposa. Assim, outro ponto que surge é a presença do escravo, desde que este tenha se tornado escravo naquilo que foi considerado por Locke como guerra justa. Ao tornarem-se escravos por meio de um ato de guerra justa, ficam sobre o domínio de algum senhor e, dessa forma, se tiverem alguma propriedade, perdem o direito a ela, pois como a vida lhes fez escravos, também as propriedades de seus bens passam a pertencer a seu dono, ao ficarem no estado de escravidão, não podendo possuir mais absolutamente nada, nem a própria vida. Não participam também da sociedade civil, visto que esta tem como principal objetivo proteger a propriedade.

Tendo esses homens, tal como digo, perdido o direito à vida com ela as liberdades, bem como suas propriedades, e estando no estado de escravidão, não sendo capazes de posse nenhuma, não podem pois ser considerados parte da sociedade civil, uma vez que o principal fim desta é a preservação da propriedade. (LOCKE, 1998, p. 456). 
Embora no ponto de vista apresentado por Locke a família seja uma organização muito importante, ela não se constitui em uma organização política, pois está colocada dentro de uma série de limites de organização bem mais restritos. Sendo assim, é fácil compreender que uma sociedade política é formada por aqueles que estão unidos em um corpo único e têm uma lei estabelecida comum e uma legislação à qual apelar com autoridade para decidir sobre as controvérsias entre eles e punir os infratores que não estão em sociedade civil uns com os outros. E, nesta medida, os integrantes do grupo familiar, ou a família como um todo, são parte integrante da sociedade civil. Aqueles que não tenham essa vida em comunidade estão no estado de natureza, sendo cada um juiz de si mesmo e tendo também que executar as sentenças quando houver necessidade. Locke investiga sempre as questões afirmando que é necessário ultrapassar o limite da organização familiar para a formação da sociedade política. Demonstra ele, desta forma, que embora a família forneça um núcleo importante dentro da estrutura social, os homens devem evoluir constantemente para uma melhor organização e estruturação das leis, objetivando-se, assim, a formação sólida da sociedade civil, como afirma Locke:

Portanto, sempre que qualquer número de homens estiver unido numa sociedade de modo que cada um renuncie ao poder executivo da Lei da natureza e o coloque nas mãos do público, então, e somente então, haverá uma sociedade política ou civil. E tal ocorre sempre que qualquer número de homens no estado de natureza entra em sociedade para formar um povo, um corpo político sob um único governo supremo, ou então quando qualquer um se junta e se incorpora a qualquer governo já formado. (LOCKE, 1998, p. 460).

Ao continuar seu raciocínio, Locke mostrará também a sua visão quanto à necessidade da superação de duas questões vistas por ele como importantes na construção da sociedade política ou civil. A primeira é romper com o estado de natureza e a segunda com um possível governo absolutista. Essas são condições fundamentais para o processo evolutivo da sociedade civil como também uma evolução da racionalidade humana.

E isso retira os homens do estado de natureza e os coloca no de uma sociedade política, estabelecendo um juiz na terra, investido de autoridade para resolver todas as controvérsias e reparar os danos que possam advir a qualquer membro dessa sociedade - juiz este que é o legislativo ou os 
magistrados por ele nomeados. E sempre que qualquer número de homens, seja qual for a maneira de associação, não tiver recurso a um tal poder decisivo de apelo, tais homens se encontrarão ainda no estado de natureza. (LOCKE, 1998, p. 460-461).

Ao ressaltar os valores e benefícios da sociedade civil, Locke lembra a sua importância por esta permitir que havendo uma organização social e política entre os homens, isto solucionaria questões importantes quanto aos conflitos de interesses sociais. Enquanto que, no estado de natureza, havia dificuldade para que se pudesse arbitrar em relação a determinados problemas por não ter uma regra ou corpo jurídico que decidisse sem isenção quanto ao interesse das duas partes, na sociedade civil tal problema poderia ser solucionado a partir de organismos jurídicos e com a aplicação de leis constituídas pela sociedade política. Em uma outra perspectiva ainda, Locke faz uma dura crítica ao Estado absolutista por ser este, segundo ele, uma manifestação de controle tão grande que certamente o diálogo, assim como a discussão jurídica, estaria impossibilitado. E mais uma vez fica evidenciada a recusa de Locke ao absolutismo, em suas palavras:

Fica, portanto, evidente que a monarquia absoluta, que alguns consideram o único governo no mundo, é de fato incompatível com a sociedade civil, e portanto não pode ser, de modo algum, uma forma de governo civil. Pois sendo o fim da sociedade civil evitar e remediar aquelas inconveniências do estado de natureza que necessariamente decorrem do fato de cada homem ser juiz em causa própria, estabelecendo uma autoridade notória à qual cada membro dessa sociedade possa apelar, a todo dano recebido ou a qualquer controvérsia surgida, e a que cada um deve obedecer; sempre que houver pessoas desprovidas de uma tal autoridade à qual apelar para a decisão de quaisquer diferenças entre elas, essas pessoas, se encontrarão ainda no estado de natureza, do mesmo modo qualquer príncipe absoluto em relação àqueles que estiverem sobre seu domínio. (LOCKE, 1998, p. 461).

Com a intenção de demonstrar toda a sua recusa ao autoritarismo absolutista, Locke afirma também que quando os homens ficam sob o domínio de um senhor absoluto, corre-se assim o risco de ter não somente o seu controle pessoal e o da família, como também a própria defesa das suas propriedades ficaria prejudicada, pois a forma de se arbitrar nesse caso se daria dentro da sociedade política e sendo o governo absolutista, afirma Locke: 
Enquanto no estado de natureza ordinário tem ele a liberdade de julgar seu próprio direito e, de acordo com o que estiver a seu alcance sustentálo, neste caso, sempre que sua propriedade for invadida por vontade ou ordem de seu monarca, ele não só não tem a quem apelar, tal como devem ter os que vivem em sociedade, mas é como se fosse degradado do estado comum das criaturas racionais, sendo-lhe negada a liberdade de julgar e defender seu próprio direito, de modo que fica exposto a todas as misérias e inconvenientes que um homem possa temer por parte de alguém que, além de encontrar-se num estado irrestrito de natureza, é ainda corrompido pela adulação e está armado com o poder. (LOCKE, 1998, p. 463).

Garantir a confirmação de uma sociedade política e civil e por consequiência de um governo livre e que permita o exercício das liberdades individuais é uma constante no pensamento de Locke. Tal atitude assumida por ele conduz a um determinado fỉm, que é a proteção da propriedade particular dos indivíduos, onde esta seria, se não a única, ao menos a principal função de uma comunidade política ou de um governo, nas palavras do próprio Locke:

O mando principal, com a arbitragem das diferenças delas, passasse, por consentimento tácito, às suas mãos, sem nenhuma outra preocupação além da garantia que tinham de sua probidade e sabedoria; e, no entanto, quando o tempo, conferindo a autoridade e (segundo gostariam de convencer-nos alguns homens) caráter sagrado aos costumes a que inocência negligente e imprevidente dos primeiros tempos dera início, trouxe sucessores de outro feito, as pessoas, não vendo suas propriedades em segurança sob o governo tal como então era (conquanto tenha o governo não outro fim além da preservação da propriedade), não puderam mais sentir-se seguras ou tranqüilas, e tampouco considerar-se em sociedade civil até que a legislatura fosse depositada em corpos coletivos de homens, sejam estes chamados senado, parlamento ou o que bem nos aprouver. (LOCKE, 1998, p. 465).

A organização política como é apresentada não parece distinguir claramente a divisão do poder para a forma em que ele foi compreendido pelos primeiros pensadores modernos do Século XVIII. Entretanto, as contribuições por ele deixadas ao separar a política e o governo da religião precederam a separação que mais tarde seria delimitada pelos modernos iluministas.

Enquanto que Montesquieu, por exemplo, separa as três formas de poder do Estado em: Executivo, Legislativo e Judiciário, Locke, por seu lado, não chega a fazer esta distinção com a clareza que foi posteriormente 
desenvolvida pelo filósofo francês. Dentro do momento pensado e vivido por Locke, uma separação nas três formas de poder nunca foi um problema que necessitasse de definição. O ponto onde de fato houve uma preocupação maior que era preciso clarear era que a sociedade civil ou política deveria ter uma maneira direta de controle sobre o exercício do governo. Assim, quando Locke desenvolve suas idéias sobre a forma de exercitar o poder, não há uma distinção clara e objetiva como compreendemos hoje, mas sim uma proposta de diferentes formas para o exercício deste poder e que, então, a participação nele dos integrantes da sociedade civil é fundamental. O governo não é, portanto, exclusividade de um Senhor todo poderoso, mas deve ser construído e controlado por aqueles que vivem na sociedade e dela participam.

Neste particular, Locke apresenta claramente a postura de um pensador próximo daquilo que seria conhecido posteriormente como liberal. Defende a importância do governo e não abandona os mecanismos de controle do poder estatal. Neste ponto particular, a sociedade civil torna-se crucial por representar, nas suas várias formas de organização, mecanismos onde os cidadãos possam, por meio da vida política e do processo de fiscalização dos governos, garantir a própria liberdade pessoal. Então, naquilo que concerne à importância da sociedade civil no pensamento político deste inglês, podemos afirmar ser a comunidade ou sociedade civil determinante para a maneira como ele via o Estado, a política e a vida em comunidade. Uma comunidade de direitos e obrigações não deve isentar ninguém de suas responsabilidades, nem mesmo os seus governantes. Quem mais pode questioná-los deve ser a própria sociedade, que em outros termos seria a sociedade civil organizada e nela representada a vontade dos indivíduos participantes de toda a comunidade.

\section{A formação das sociedades políticas}

O ponto de partida escolhido por Locke para a formação da sociedade política é a liberdade individual compreendida por ele como um direito inalienável para a condição humana. Essa liberdade que é adquirida pelos homens no estado de natureza só poderá ser abdicada, por parte dos homens, se for para formar, com outros indivíduos, a sociedade civil. Vivendo desta forma, em comunidade, os homens buscarão garantias para a manutenção da liberdade, podendo, a partir daí, defender-se quando houver atentado contra às suas vidas, liberdades ou propriedades. Nenhuma outra atitude justificaria que um indivíduo abra mão de sua liberdade e aquele que eventualmente atentar contra a vida do grupo que 
forma a comunidade poderá tornar-se escravo de um determinado integrante da comunidade e é esta a forma de escravidão que Locke considerou quando da chamada guerra justa. Onde houve atentado contra a liberdade individual e o risco que foi colocado àquele que sofreu o atentado justificaria a atitude deste em relação ao outro para que previna a si e a sua família como a própria comunidade de futuros atentados que são inadmissíveis por ferir a liberdade individual.

Por ter havido consentimento de um grupo de homens livres em formar uma comunidade, estão estes vivendo em sociedade civil, o que os levará a formarem o governo e, desta forma, passam a incorporar um corpo político onde a maioria tem o direito de agir e deliberar pelos demais. Locke coloca duas questões importantes: primeiramente, a participação na vida social e política da comunidade e, em seguida, a noção de maioria que se tornou importante para o princípio de democracia representativa cujo o conceito seria melhor desenvolvido a partir do século XVIII.

\begin{abstract}
Sendo todos os homens, como já foi dito, naturalmente livres, iguais e independentes, ninguém pode ser privado dessa condição nem colocado sob o poder político de outrem sem o seu próprio consentimento. A única maneira pela qual uma pessoa qualquer pode abdicar de sua liberdade natural e revestir-se dos elos da Sociedade Civil é concordando com outros homens em juntar-se e unir-se em uma comunidade, para viverem confortável, segura e pacificamente uns com outros num gozo seguro de suas propriedades e com maior segurança contra aqueles que dela não fazem parte. (LOCKE, 1998, p. 468).
\end{abstract}

Os homens, ao formarem uma comunidade, criam vínculos importantes para o seu crescimento que possibilitam a participação na vida política da sociedade. Dessa maneira, também recusam o controle do governante soberano e absoluto, o que leva Locke a contestar os princípios absolutistas que foram defendidos durante o século dezessete e anteriormente. A formação da sociedade política sendo um ato de vontade, e de consentimento, opõe-se necessariamente às formas de governo totalitárias. As decisões devem ser tomadas pela maioria, pois todos são, além de integrantes da comunidade, também participantes do processo político e do corpo único da comunidade, o que evidencia a importância dada aos indivíduos e que estes tomam decisões fundamentadas no princípio da liberdade.

Disso decorre outro ponto importante, que é a realização de assembléias com o propósito de tomar decisões. Decisões que serão respeitadas nas instâncias de governo ou corpo político constituído. As ações das assembléias 
têm o poder de construção de leis positivas e a ação da maioria, que se dá por meio da participação, passará a constituir a vontade do todo. Utilizando-se dos princípios da lei da natureza e do uso da razão, formará o poder de todo o corpo político. A formulação de leis que realizam a construção política da sociedade se dará, portanto, pela ação livre dos homens que vivem em comunidade construída a partir da vontade individual. E estas leis permitirão a participação nas decisões tomadas de forma direta e deverá reger o funcionamento da sociedade.

Pois quando um número qualquer de homens formou, pelo consentimento de cada indivíduo, uma comunidade, fizeram eles de tal comunidade, dessa forma, um corpo único, com o poder de agir como um corpo único, o que se dá apenas pela vontade e determinação da maioria. (LOCKE, 1998, p. 469).

Com o intento de demonstrar a necessidade da participação direta, como também o de garantir o respeito às decisões que foram criadas no corpo político único, Locke desenvolve a idéia de pacto, o que ele chama de pacto original, pois este teria sido estabelecido entre os homens em um tempo bastante longínquo. É por meio deste pacto que os homens se incorporam a uma determinada sociedade, se não fosse assim, os homens teriam permanecido no estado de natureza. O que aparece, portanto, é a idéia de que os homens estão com a sociedade política, amadurecendo as suas condições de seres racionais, pois a vida em comunidade rompe com o estado de natureza e cria-se, assim, para os homens, uma superação, que é a própria condição para a saída do estado de natureza, colocando também um maior compromisso e responsabilidade frente à comunidade. Assim poderão, por meio do livre pensar e agir humanos, formar uma sociedade que lhes pareça melhor.

Do contrário, esse pacto original, pelo qual ele, juntamente com outros, se incorpora a uma sociedade, não teria nenhum significado e não seria pacto algum, caso ele fosse deixado livre e sob nenhum outro vínculo além dos que tinha antes no estado de natureza. Tal liberdade seria ainda tão grande como a que ele dispunha antes do pacto e como tem qualquer um no estado de natureza, que pode submeter-se e consentir a quaisquer atos que julgar conveniente. (LOCKE, 1998, p. 470).

O que Locke destaca posteriormente é a convicção que devem ter os homens que saíram do estado de natureza, firmaram um pacto e construíram uma sociedade política. No entanto, o que ele demonstra com bastante 
determinação é o fato de que as sociedades não são construídas para que sejam facilmente dissolvidas. Sendo assim, ao demonstrar que as decisões estão sendo sempre tomadas pela maioria, ou seja, que há participação dos integrantes da sociedade, portanto, ela não será facilmente dissolvida, pois a base que garante a sua sustentação é a integração por parte dos membros que compõem a comunidade e esta será mantida.

Quando deixa o estado de natureza, formando a sociedade política, cada indivíduo deve compreender que abriu mão de parte da sua liberdade. Este ato deveu-se primeiro: à busca da integração com os demais membros da comunidade e, em segundo lugar, à busca de maior proteção para a sua vida e seus bens, deve compreender ainda que obedecerá à vontade da maioria e que há, portanto, uma troca que tem como objetivo dar-lhe segurança e proteção:

Por conseguinte, o que inicia e de fato constituí qualquer sociedade política não passa do consentimento de qualquer número de homens livres capazes de uma maioria no sentido de se unirem e incorporarem a uma tal sociedade. E é isso, e apenas isso, que dá ou pode dar origem a qualquer governo legítimo no mundo. (LOCKE, 1998, p. 472).

Ao continuar demonstrando a importância de consentimento dos homens na formação dos governos, Locke faz referências a exemplos que, segundo ele, se deram pela história e que podem comprovar a necessidade de concordância dos homens para a formação do governo. Locke trabalha com estes exemplos porque ele os considera importantes para a comprovação de fatos presentes em seus argumentos.

Com o intento de confirmar as suas hipóteses, Locke segue afirmando a importância do consentimento para que, desta forma, os governos não sejam enfraquecidos e facilmente destituídos. A atitude consciente daquele que integrará a comunidade poderá garantir a boa manutenção dos governos livremente formados:

Portanto, embora olhando para traz tão longe quanto os registros nos apresentem quaisquer relatos do povoamento do mundo e da história das nações, encontremos comumente o governo nas mãos de um único homem, tal não invalida o que afirma, a saber, que o início da sociedade política depende do consentimento dos indivíduos em juntarem-se e formarem uma única sociedade - os quais, estando assim incorporados, poderiam estabelecer a forma de governo que julgassem mais adequada. (LOCKE, 1998, p. 477). 
Exercer o poder com responsabilidade é fundamental para o bom governante e em não havendo tal postura por parte daqueles que governam, fica justificada até mesmo o afastamento do poder de quem esteja no exercício daquele determinado governo. Assim, o julgamento dos integrantes da sociedade por parte dos responsáveis pela condução adequada do Estado está perfeitamente admitido dentro da sociedade política, como afirma Locke:

E, portanto, nenhum embate entre governantes e povo acerca de governos ou governantes; entretanto, quando a ambição e o Fausto de idades ulteriores quiseram reter e aumentar o poder sem desempenhar as funções pelas quais estes lhes havia sido concebido e, ajudados pela adulação, ensinaram os príncipes a ter interesses distintos e separados dos de seus povos, os homens julgaram necessários examinar com mais cuidado as origens e os direitos do governo e encontrar maneiras de restringir os excessos e de evitar os abusos desse poder que haviam confiado às mãos de outrem apenas para o próprio bem deles e que viam estar sendo usados para prejudicá-los. (LOCKE, 1998, p. 485).

Em seguida, Locke procura, por meio da rejeição dos governos monarquistas absolutos, demonstrar que o governo que consegue manter-se no poder é aquele em que a sua constituição é pacífica, ou seja, há concordância da comunidade. Sugere também que existem governos conquistados por meio da guerra e que estes acabarão se constituindo em uma monarquia absoluta.

Embora nunca houvessem sonhado que a monarquia fosse de direito divino, do que nunca ouvimos falar entre os homens até que nos fosse revelada pela teologia destes últimos tempos, nem jamais admitissem que o poder paterno tivesse direito ao domínio ou que fosse o fundamento de todo governo. E tudo isso deve bastar para mostrar que, tanto quanto possa elucidar-nos a história temos razões para concluir que todos os inícios pacíficos de governos basearam-se no consentimento do povo. (LOCKE, 1998, p. 486).

A sociedade política é caracterizada pelo poder que tem para preservar a propriedade de seus membros. Um poder que cada pessoa tinha no estado de natureza, mas concorda, por consenso e contrato, em abdicar dele e colocá-lo "nas mãos da comunidade". A comunidade torna-se o árbitro por regras fixas estabelecidas e aplicadas igualmente a todas as partes em disputa. É a unificação em um só corpo, e ter uma lei comum instituída e uma judicatura a quem recorrer, com autoridade para decidir controvérsias entre as partes e punir aos que não obedecem às normas da comunidade. 
Desse modo, é fácil distinguir quem está e quem não está em sociedade política. Aqueles que estão unidos em um corpo único e têm uma lei estabelecida comum e uma judicatura à qual apelar, com autoridade para decidir sobre as controvérsias entre eles e punir os infratores, estão em sociedade civil uns com os outros. Aqueles, porém, que não têm em comum uma tal possibilidade de apelo, explico-me, na Terra, vivem ainda em estado de natureza, sendo cada qual, onde não houver outro, juiz por si mesmo e executor - o que, como antes demonstrei, constitui o perfeito estado de natureza. (LOCKE, 1998, p. 458-459).

É importante compreender que o poder natural que cada homem tem no estado de natureza não é concedido àqueles que governam, mas ao público, ao corpo político, o qual, por sua vez, autoriza indivíduos como seus representantes a fazer leis para o bem público da sociedade. $\mathrm{O}$ ato de formação de uma comunidade vem primeiro, seguindo então a criação de um corpo político com forma e estrutura. O poder que é delegado a legisladores na sociedade civil retorna ao povo quando a confiança depositada neles foi violada.

\section{Conclusão}

Alguns outros exemplos específicos podem ser encontrados na obra do autor, segundo ele, onde a terra é escassa, as diversas comunidades fixaram os limites dos respectivos territórios e, por meio de leis dentro deles, regularam as propriedades das pessoas privadas de sua sociedade e, desse modo, mediante pacto e acordo, estabeleceram a propriedade que o trabalho e a indústria começaram. Ele também menciona o contrato temporário entre senhor e servo; o servo vende uma parcela do seu tempo e serviço. Em sua análise da propriedade, Locke mostrou como na sociedade pré-política, onde tudo é comum, a propriedade privada podia ser adquirida sem qualquer pacto expresso. Quando o homem passou a atribuir valor ao ouro e à prata, ele encontrou um modo de ter possessões desiguais e desproporcionais mediante um consentimento tácito e voluntário, mas não por um pacto.

É a formação da sociedade política ou civil, no entanto, que lhe vem à mente quando é mencionado o termo contrato. Os homens fazem várias promessas ou pactos com outros no estado de natureza, assim como dentro da sociedade civil. Um pacto pelo qual os homens concordam, mutuamente e em conjunto, em formar uma comunidade e fundar um corpo político, transfere-os do estado de natureza para a sociedade civil. Tal ponto é descrito por ele como 
pacto original por meio do qual cada homem incorpora-se aos outros em uma sociedade, com obrigações para todos e cada membro renuncia aos poderes que tinha no estado de natureza, cedendo agora esse poder à maioria. É esse pacto que dá, ou poderia dar, início a qualquer governo legítimo no mundo. Após o início da Sociedade Civil, uma pessoa que viva nesse país está sujeita aos seus benefícios e proteção, mas tal pessoa não é membro dessa comunidade. A filiação só se verifica, em suas análises, por envolvimento positivo, promessa e pacto expressos. Assim então é que a comunidade poderia funcionar como uma via de direitos e obrigações garantidores da liberdade individual.

\section{Referência}

LOCKE, John. Dois tratados sobre o Governo. Tradução Júlio Fischer. São Paulo: Martins Fontes, 1998.

Recebido: $12 / 01 / 2008$

Received: 01/12/2008

Aprovado: 23/02/2008

Approved: 02/23/2008 